\title{
Comparison of the Viability of Cryopreserved Fat Tissue in Accordance with the Thawing Temperature
}

\author{
So-Min Hwang, Jong-Seo Lee, Hyung-Do Kim, Yong-Hui Jung, Hong-Il Kim \\ Aesthetic, Plastic and Reconstructive Surgery Center, Good Moonhwa Hospital, Busan, Korea
}

Background Adipose tissue damage of cryopreserved fat after autologous fat transfer is inevitable in several processes of re-transplantation. This study aims to compare and analyze the survivability of adipocytes after thawing fat cryopreserved at $-20^{\circ} \mathrm{C}$ by using thawing methods used in clinics.

Methods The survival rates of adipocytes in the following thawing groups were measured: natural thawing at $25^{\circ} \mathrm{C}$ for 15 minutes; natural thawing at $25^{\circ} \mathrm{C}$ for 5 minutes, followed by rapid thawing at $37^{\circ} \mathrm{C}$ in a water bath for 5 minutes; and rapid thawing at $37^{\circ} \mathrm{C}$ for 10 minutes in a water bath. The survival rates of adipocytes were assessed by measuring the volume of the fat layer in the top layers separated after centrifugation, counting the number of live adipocytes after staining with trypan blue, and measuring the activity of mitochondria in the adipocytes.

Results In the group with rapid thawing for 10 minutes in a water bath, it was observed that the cell count of live adipocytes and the activity of the adipocyte mitochondria were significantly higher than in the other two groups $(P<0.05)$. The volume of the fat layer separated by centrifugation was also measured to be higher, which was, however, not statistically significant.

Conclusions It was shown that the survival rate of adipocytes was higher when the frozen fat tissue was thawed rapidly at $37^{\circ} \mathrm{C}$. It can thus be concluded that if fats thawed with this method are re-transplanted, the survival rate of cryopreserved fats in transplantation will be improved, and thus, the effect of autologous fat transfer will increase.

Keywords Autografts / Cryopreservation / Fats
Correspondence: Jong-Seo Lee Aesthetic, Plastic and Reconstructive Surgery Center, Good Moonhwa Hospital, 119 Beom-il ro, Dong-gu, Busan 601-803, Korea

Tel: +82-51-630-0199

FAx: +82-51-630-0145

E-mail: blueorange1009@hanmail.net

No potential conflict of interest relevant to this article was reported.

\section{INTRODUCTION}

Autologous fat transfer is a simple procedure that does not show foreign body and immune reactions, and abundant donor sites are available. Therefore, it is used widely in the area of plastic surgery for reconstructive and cosmetic purposes [1]. However, it has a disadvantage: it is difficult to predict the transplant survival rates due to the absorption or necrosis of a variable portion of the transplanted adipose tissue after autologous fat transfer [2]. Survival rates ranging from $30 \%$ to $80 \%$ have been reported [3-5], and due to this variability, overcorrection or re-transplantation has been implemented in order to address the high ab- 
sorption rates of adipose tissue. However, since overcorrection leads to unnatural cosmetic outcomes and re-transplantation brings with it the burden of re-surgery, the recent trend is to cryopreserve residual adipose tissue after a fat transfer to be reused in the case that re-transplantation is needed [6].

When the adipose tissue is reused after storage, the survival rate of the adipocytes is important since they have a great impact on the engraftment of adipose tissue after the re-injection $[7,8]$. Although a number of studies have examined the fat sampling and freezing processes [7-12], relatively less analysis of the thawing process has been performed. Because the thawing process is essential for the reuse of the cryopreserved autologous fat, appropriate thawing methods need to be studied to minimize cell damage. Therefore, this study aims to objectively analyze the difference in the survival rates of adipocytes depending on the thawing method of fats cryopreserved at $-20^{\circ} \mathrm{C}$.

\section{METHODS}

\section{Research subjects}

After obtaining approval from the Institutional Review Board (2013-03) and a signed consent to participate, abdominal subcutaneous fats for autologous transfer were harvested from a total of 20 patients ( 19 females and 1 male; $23-66$ years of age, mean age: 47.4 years) between January 2011 and January 2013. Adipose tissue was harvested by means of liposuction using a 10 $\mathrm{mL}$ syringe attached to $3.0 \mathrm{~mm}$ diameter Mercedes pattern or Pyramid pattern suction cannula and centrifuged at 3,000 rpm for 3 minutes. The supernatant lipid layer and the bottom plasma and aqueous layer were removed, and only the middle layer, which contained the fat cells, was saved. Autologous fat transfer was carried out with these fats, and residual adipose tissues were cryopreserved at $-20^{\circ} \mathrm{C}$ for the re-transplantation. These cryopreserved residual fats were used for this study. The patients whose fat was collected were in good health. The patients were given adequate explanation of the research on human-derived material, and they gave their consent before the experiment.

\section{Research methods}

Thawing methods

Methods of thawing cryopreserved fats currently in clinical use were used. In experimental group A, natural thawing at room temperature $\left(25^{\circ} \mathrm{C}\right)$ for 15 minutes was used. Natural thawing at room temperature for 5 minutes followed by rapid thawing for 5 minutes in a $37^{\circ} \mathrm{C}$ bath (GEMINI, Robins Scientific, USA) was used in experimental group $\mathrm{B}$, while rapid thawing for 10 minutes in a $37^{\circ} \mathrm{C}$ bath was used in experimental group $\mathrm{C}$. The thawing time was set on the basis of the time needed for samples
Fig. 1. Preparation of the samples for each experimental group

Using $9 \mathrm{~mL}$ of fat per person, we prepared 3-mL samples for each experimental group.

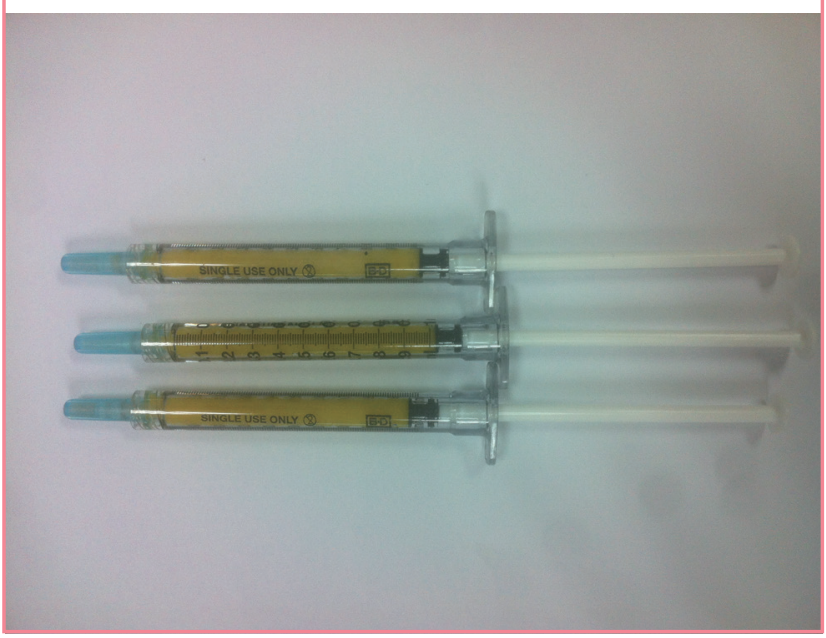

to reach the thawing temperature in each experimental group in a preliminary study. The 9-mL sample per patient was divided into three 3-mL samples for each experimental group (Fig. 1).

\section{Measurement of the survival rates of adipocytes Measurement of the volume of the lipid layer after centrifugation}

After centrifugation at 3,000 rpm for 3 minutes by using a centrifuge (Centrifuge 5424R, Eppendorf, Germany), the volume of the supernatant lipid layer was measured and the degree of damage of the adipocytes was evaluated indirectly through this [13].

\section{Measurement of the number of adipocytes that survived}

After centrifuging the thawed adipose tissues in each group at $3,000 \mathrm{rpm}$ for 3 minutes, $0.1 \mathrm{~mL}$ of the adipose tissue in the middle layer of each sample was collected and to each sample, type I collagenase solution (Sigma, Germany) was added and mixed uniformly. After histolysis for 3 hours in an incubator at $37^{\circ} \mathrm{C}$, the treated tissues were centrifuged at 3,000 rpm for 10 minutes. $10 \mu \mathrm{L}$ of the sample was collected from the layer rich in the adipose tissue immediately below the supernatant lipid layer and stained with trypan blue. The number of live cells in a $1-\mu \mathrm{L}$ sample was counted once by using the cell counting chamber [14].

\section{Measurement of mitochondrial activity}

The mitochondrial activity of the adipocytes was measured using the (2,3-bis-5-carbonyl)-2H-tetrazolium hydroxide (XTTtetrazolium) assay. After centrifuging the thawed adipose tissues in each group at 3,000 rpm for 3 minutes, $0.2-\mathrm{mL}$ samples of ad- 
ipose tissue from the middle layer were collected and divided on a 24-well plate, and $0.5 \mathrm{~mL}$ of Dulbecco's modified Eagle's medium was added to each well containing the samples. After mixing $5 \mathrm{~mL}$ of the XTT reagent and $100 \mu \mathrm{L}$ of activator using a Cell Proliferation Kit (Biological Industries, Israel), $1.5 \mathrm{~mL}$ of the mixture was added to each well of the sample plate, which was in turn incubated at $37^{\circ} \mathrm{C}$ for 3 hours. After centrifugation at $16,000 \mathrm{rpm}$ for 20 minutes, the supernatant layers were collected and their respective optical density was measured by using a 492-nm spectrophotometer [8].

\section{Statistical methods}

The Kruskal-Wallis test and the Mann-Whitney test were performed for the data analysis using SPSS ver. 20.0 (IBM Co., Somers, NY, USA), and a P-value less than 0.05 was considered to be significant.

\section{RESULTS}

The volume of the lipid layer measured after centrifugation was 6-750 $\mu \mathrm{L}$ (mean, $297.3 \mu \mathrm{L}$ ) in the group naturally thawed at room temperature, 5-1,050 $\mu \mathrm{L}$ (mean, $309.5 \mu \mathrm{L}$ ) in the group thawed rapidly after natural thawing, and 5-800 $\mu \mathrm{L}$ (mean,

\section{Table 1. Measurement of the lipid volume in the upper layer after centrifugation}

\begin{tabular}{|c|c|c|c|}
\hline \multirow{2}{*}{ Sample } & \multicolumn{3}{|c|}{ Lipid volume $(\mu \mathrm{L})$} \\
\hline & Group A ${ }^{\text {a) }}$ & Group Bb) & Group Cc) \\
\hline 1 & 30 & 5 & 10 \\
\hline 2 & 750 & 1,050 & 700 \\
\hline 3 & 700 & 820 & 700 \\
\hline 4 & 280 & 50 & 80 \\
\hline 5 & 100 & 200 & 90 \\
\hline 6 & 310 & 300 & 300 \\
\hline 7 & 550 & 500 & 400 \\
\hline 8 & 740 & 950 & 800 \\
\hline 9 & 210 & 210 & 190 \\
\hline 10 & 230 & 300 & 350 \\
\hline 11 & 20 & 15 & 10 \\
\hline 12 & 210 & 210 & 200 \\
\hline 13 & 200 & 150 & 150 \\
\hline 14 & 60 & 50 & 50 \\
\hline 15 & 550 & 400 & 300 \\
\hline 16 & 150 & 100 & 80 \\
\hline 17 & 260 & 150 & 150 \\
\hline 18 & 140 & 110 & 100 \\
\hline 19 & 6 & 20 & 5 \\
\hline 20 & 450 & 600 & 200 \\
\hline $\begin{array}{l}\text { Average } \pm \text { standard } \\
\text { deviation }\end{array}$ & $297.3 \pm 236.7$ & $309.5 \pm 309.2$ & $243.3 \pm 233.9$ \\
\hline
\end{tabular}

$243.3 \mu \mathrm{L}$ ) in the group thawed rapidly (Table 1). Overall, the volume of the lipid layer measured in the group thawed rapidly was somewhat lower, but the difference was not statistically significant $(\mathrm{P}=0.630)$.

The number of live adipocytes was counted by trypan blue staining. Among the live cells observed in the $1-\mu \mathrm{L}$ samples in the cell counting chamber, only the cells whose diameter was greater than $50 \mu \mathrm{m}$ were counted. It was found that 3-37 cells/ $\mu \mathrm{L}$ (mean, 19.2 cells $/ \mu \mathrm{L}$ ) were counted in the group naturally thawed at room temperature, $6-33$ cells/ $\mu \mathrm{L}$ (mean, 20.6 cells/ $\mu \mathrm{L}$ ) in the group thawed rapidly after natural thawing, and 8-60 cells $/ \mu \mathrm{L}$ (mean, 27.9 cells $/ \mu \mathrm{L}$ ) in the group thawed rapidly (Table 2 ). In comparing the three groups, the number of adipocytes counted in the group rapidly thawed was statistically significantly higher $(P=0.035)$ (Fig. 2).

After the reaction between the samples and the XTT reagent, the optical density (OD) of the upper layer was measured. The OD was $0.441-0.884$ (mean, 0.579 ) in the group naturally thawed at room temperature, $0.448-0.930$ (mean, 0.587 ) in the group thawed rapidly after natural thawing, and 0.454-1.061 (mean, 0.667 ) in the group thawed rapidly (Table 3 ). In the comparison of these three groups, the mitochondrial activity in the group thawed rapidly was shown to be significantly higher $(\mathrm{P}=0.020)$.

Table 2. The live adipocyte count after the trypan blue staining of each group

\begin{tabular}{|c|c|c|c|}
\hline \multirow{2}{*}{ Sample } & \multicolumn{3}{|c|}{ Live adipocyte count (number/ $\mu \mathrm{L}$ ) } \\
\hline & Group $A^{\text {a) }}$ & Group $B^{\text {b) }}$ & Group $C^{c)}$ \\
\hline 1 & 37 & 33 & 60 \\
\hline 2 & 26 & 32 & 34 \\
\hline 3 & 28 & 32 & 36 \\
\hline 4 & 28 & 33 & 30 \\
\hline 5 & 17 & 18 & 34 \\
\hline 6 & 17 & 20 & 26 \\
\hline 7 & 20 & 26 & 40 \\
\hline 8 & 32 & 20 & 29 \\
\hline 9 & 23 & 16 & 39 \\
\hline 10 & 21 & 15 & 29 \\
\hline 11 & 17 & 21 & 25 \\
\hline 12 & 15 & 17 & 20 \\
\hline 13 & 19 & 33 & 28 \\
\hline 14 & 6 & 11 & 19 \\
\hline 15 & 23 & 13 & 23 \\
\hline 16 & 3 & 6 & 8 \\
\hline 17 & 8 & 16 & 23 \\
\hline 18 & 12 & 15 & 16 \\
\hline 19 & 10 & 14 & 14 \\
\hline 20 & 22 & 21 & 25 \\
\hline $\begin{array}{l}\text { Average } \pm \text { standard } \\
\text { deviation }\end{array}$ & $19.2 \pm 8.5$ & $20.6 \pm 8.0$ & $27.9 \pm 10.9$ \\
\hline
\end{tabular}




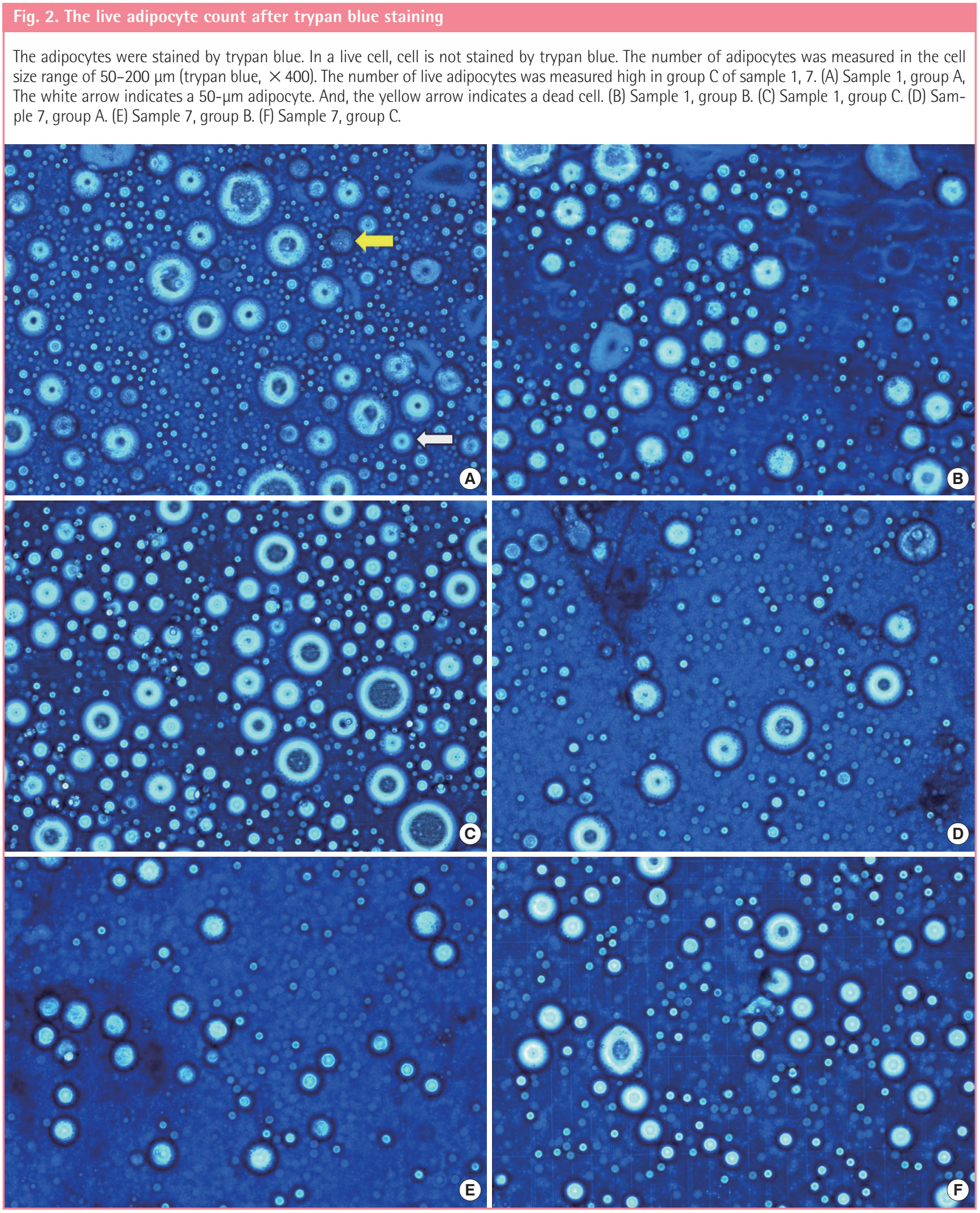


Table 3. Measurement of mitochondrial activity by XT assay

\begin{tabular}{|c|c|c|c|}
\hline \multirow{2}{*}{ Sample } & \multicolumn{3}{|c|}{ Mitochondrial activity (optical density) } \\
\hline & Group $A^{\text {a) }}$ & Group $B^{\text {b) }}$ & Group $C^{c)}$ \\
\hline 1 & 0.508 & 0.492 & 0.552 \\
\hline 2 & 0.498 & 0.448 & 0.546 \\
\hline 3 & 0.508 & 0.511 & 0.544 \\
\hline 4 & 0.474 & 0.454 & 0.589 \\
\hline 5 & 0.534 & 0.494 & 0.566 \\
\hline 6 & 0.597 & 0.488 & 0.656 \\
\hline 7 & 0.529 & 0.524 & 0.647 \\
\hline 8 & 0.572 & 0.591 & 0.828 \\
\hline 9 & 0.570 & 0.596 & 0.663 \\
\hline 10 & 0.536 & 0.539 & 0.637 \\
\hline 11 & 0.664 & 0.646 & 0.720 \\
\hline 12 & 0.716 & 0.752 & 0.840 \\
\hline 13 & 0.669 & 0.912 & 0.871 \\
\hline 14 & 0.884 & 0.930 & 1.061 \\
\hline 15 & 0.497 & 0.542 & 0.667 \\
\hline 16 & 0.441 & 0.496 & 0.522 \\
\hline 17 & 0.555 & 0.509 & 0.589 \\
\hline 18 & 0.738 & 0.721 & 0.743 \\
\hline 19 & 0.623 & 0.634 & 0.642 \\
\hline 20 & 0.484 & 0.453 & 0.454 \\
\hline $\begin{array}{l}\text { Average } \pm \text { standard } \\
\text { deviation }\end{array}$ & $0.579 \pm 0.106$ & $0.587 \pm 0.139$ & $0.667 \pm 0.141$ \\
\hline \multicolumn{4}{|c|}{ 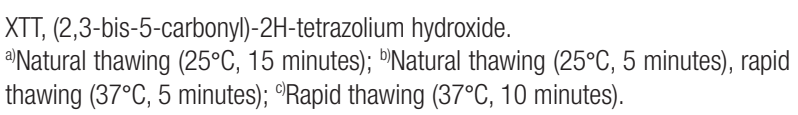 } \\
\hline
\end{tabular}

\section{DISCUSSION}

The reuse of cryopreserved fat requires a thawing process. Pu et al. [14] suggested that outcomes were better when cryopreserved fat was thawed at $37^{\circ} \mathrm{C}$. However, no method has yet been established for thawing cryopreserved fat tissue. To find a better thawing method among those commonly used in clinic, in this study, we aimed to compare the survival rates of cryopreserved fat with which different combinations of natural and rapid thawing methods were used.

A study on the survival rates of adipocytes is normally performed by live cell counting through trypan blue staining $[14,15]$, the measurement of enzyme activity using glycerol-3-phosphate dehydrogenase analysis $[14,16]$, the measurement of mitochondrial activity using XTT assay $[2,8]$ or MTT assay $[10,11]$, and the observation of cell morphology through hematoxylin and eosin staining [14].

If the cell membrane of adipocytes is disrupted, the lipid components in adipocytes spill out [8]. The degree of adipocyte disruption can be assessed indirectly by measuring the volume of the lipid layer generated during centrifugation performed after thawing the cryopreserved fat [13].
Trypan blue does not stain live cells, but rather, selectively stains dead tissues or cells. Therefore, the number of live cells can be determined by counting the cells not stained after the trypan blue staining. Adipocytes are relatively large among human cells, with a size in the range of 50-200 $\mu \mathrm{m}[17,18]$. Therefore, in order to count the number of live adipocytes, the cells that were not stained by trypan blue and were $50-200 \mu \mathrm{m}$ in size were counted.

Succinate-tetrazolium reductase is present in the respiratory chain in the mitochondria and is active in live cells. Tetrazolium salt is converted to a water-soluble formazan dye by this enzyme, and the optical density of the formazan dye can be measured with the spectrophotometric method. The XTT assay is a method for determining the viability of cells using the measured optical density $[2,8]$. The optical density measured by the XTT assay before freezing adipose tissues upon sampling was reported to be 1.304 and 0.432 in two studies $[8,19]$. It seems that the results differed due to differences in sample preparation and testing methods, and thus, neither of these values could not be regarded as the optical density of normal adipocytes.

The volume of the lipid layer measured after thawing was shown to be a bit lower in the experimental group that was thawed rapidly than in the other experimental groups, but the difference was not statistically significant $(\mathrm{P}=0.630)$. It can be concluded that each sample yielded different values since the lipid layer was not completely removed when isolating the fat cell layer after centrifugation performed before the cryopreservation of the samples.

The number of live adipocytes counted by trypan blue staining and mitochondrial activity measured through the XTT assay was statistically significantly higher in the experimental group that was thawed rapidly $(\mathrm{P}<0.05)$. This showed a similar pattern to that observed in experiments involving the thawing of other cryopreserved human tissues or cells such as sperm or fibroblasts, which the experimental group that was thawed rapidly at $37^{\circ} \mathrm{C}$ showed higher cell viability [20-22]. Martinez-Soto et al. [23] conducted a study on the effect of different thawing methods of cryopreserved sperm on their cell viability, in which one method was thawing at room temperature for 10 minutes followed by rapid thawing at $37^{\circ} \mathrm{C}$, while the other was rapid thawing entirely at $37^{\circ} \mathrm{C}$. They suggested that the experimental group thawed rapidly at $37^{\circ} \mathrm{C}$ displayed higher sperm viability.

These results suggest that the thawing method has a crucial impact on the survival of frozen cells, and therefore, an appropriate thawing method is necessary. Calamera et al. [24] suggested that the recovery of antioxidant capacity by enzymes increased with an increase in the thawing temperature. Thomson et al. [25] reported that while oxygen radicals capable of de- 
stroying nucleic acids in cells could be generated during the thawing process, these could be effectively neutralized if the cells were thawed at a high temperature.

Therefore, by comparing our experimental results for each thawing method with the findings of other studies, we observed that rapid thawing of cryopreserved fat at $37^{\circ} \mathrm{C}$ will keep mitochondrial activity high and minimize adipocyte damage during thawing. Hence, it is considered that the injection of fat having undergone rapid thawing in a water bath at $37^{\circ} \mathrm{C}$ will give better outcomes when the fat is to be thawed and injected in clinic.

However, the degree of adipocyte damage during the harvesting and storage process will be different in each sample. In addition, the difference in adipocyte viability according to the age of the person whose fat was sampled should be taken into account. Also, trypan blue staining or XTT assay has a limitation that the results come from not only adipocytes but also other live cells. Therefore, to build upon these findings, further studies should be performed by harvesting each sample under more uniform conditions, including a more homogeneous patient sample and more standardized procedures. Further, in order to more thoroughly understand the changes in adipocytes depending on the thawing methods, not only in vitro studies on adipocytes but also more advanced studies on the difference in the survival rates of adipocytes after the actual in vivo transplantation are needed.

\section{REFERENCES}

1. Piasecki JH, Gutowski KA, Lahvis GP, et al. An experimental model for improving fat graft viability and purity. Plast Reconstr Surg 2007;119:1571-83.

2. Rohrich RJ, Sorokin ES, Brown SA. In search of improved fat transfer viability: a quantitative analysis of the role of centrifugation and harvest site. Plast Reconstr Surg 2004;113: 391-5.

3. Scarborough DA, Schuen W, Bisaccia E. Fat transfer for aging skin: technique for rhytids.J Dermatol Surg Oncol 1990; 16:651-5.

4. Pereira LH, Radwanski HN. Fat grafting of the buttocks and lower limbs. Aesthetic Plast Surg 1996;20:409-16.

5. Guerrerosantos J, Gonzalez-Mendoza A, Masmela Y, et al. Long-term survival of free fat grafts in muscle: an experimental study in rats. Aesthetic Plast Surg 1996;20:403-8.

6. Shoshani O, Ullmann Y, Shupak A, et al. The role of frozen storage in preserving adipose tissue obtained by suction-assisted lipectomy for repeated fat injection procedures. Dermatol Surg 2001;27:645-7.

7. Son $\mathrm{D}$, Oh J, Choi T, et al. Viability of cells in aspirated fat tissue after 1 year cryopreservation. J Korean Soc Plast Reconstr Surg 2009;36:135-9.

8. Kim YK, Park HS, Lee HJ. Studies on the proper storage period and change of -20 degrees $\mathrm{c}$ cryopreserved adipocyte. J Korean Soc Aesthetic Plast Surg 2006;12:33-42.

9. Boschert MT, Beckert BW, Puckett CL, et al. Analysis of lipocyte viability after liposuction. Plast Reconstr Surg 2002; 109:761-5.

10. MacRae JW, Tholpady SS, Ogle RC, et al. Ex vivo fat graft preservation: effects and implications of cryopreservation. Ann Plast Surg 2004;52:281-2.

11. Macrae JW, Tholpady SS, Katz AJ, et al. Human adipocyte viability testing: a new assay. Aesthet Surg J 2003;23:265-9.

12. Cui XD, Gao DY, Fink BF, et al. Cryopreservation of human adipose tissues. Cryobiology 2007;55:269-78.

13. Matsumoto D, Shigeura T, Sato K, et al. Influences of preservation at various temperatures on liposuction aspirates. Plast Reconstr Surg 2007;120:1510-7.

14. Pu LL, Cui X, Fink BF, et al. Long-term preservation of adipose aspirates after conventional lipoplasty. Aesthet Surg J 2004;24:536-41.

15. Sommer B, Sattler G. Current concepts of fat graft survival: histology of aspirated adipose tissue and review of the literature. Dermatol Surg 2000;26:1159-66.

16. Lalikos JF, Li YQ Roth TP, et al. Biochemical assessment of cellular damage after adipocyte harvest. J Surg Res 1997; 70:95-100.

17. Jernas M, Palming J, Sjoholm K, et al. Separation of human adipocytes by size: hypertrophic fat cells display distinct gene expression. FASEB J 2006;20:1540-2.

18. O'Connell J, Lynch L, Cawood TJ, et al. The relationship of omental and subcutaneous adipocyte size to metabolic disease in severe obesity. PLoS One 2010;5:e9997.

19. Wolter TP, von Heimburg D, Stoffels I, et al. Cryopreservation of mature human adipocytes: in vitro measurement of viability. Ann Plast Surg 2005;55:408-13.

20. Verheyen G, Pletincx I, Van Steirteghem A. Effect of freezing method, thawing temperature and post-thaw dilution/ washing on motility (CASA) and morphology characteristics of high-quality human sperm. Hum Reprod 1993;8: 1678-84.

21. Mazur P, Koshimoto C. Is intracellular ice formation the cause of death of mouse sperm frozen at high cooling rates? Biol Reprod 2002;66:1485-90.

22. Guan H, Zhao Z, He F, et al. The effects of different thawing temperatures on morphology and collagen metabolism of -20 degrees $\mathrm{C}$ dealt normal human fibroblast. Cryobiology 2007;55:52-9. 
23. Martinez-Soto JC, Garcia-Vazquez FA, Gumbao D, et al. Assessment of two thawing processes of cryopreserved human sperm in pellets. Cryobiology 2011;63:131-6.

24. Calamera JC, Buffone MG, Doncel GF, et al. Effect of thawing temperature on the motility recovery of cryopreserved human spermatozoa. Fertil Steril 2010;93:789-94.

25. Thomson LK, Fleming SD, Aitken RJ, et al. Cryopreservation-induced human sperm DNA damage is predominantly mediated by oxidative stress rather than apoptosis. Hum Reprod 2009;24:2061-70. 